\title{
Theoretical Assessment of Dinitrogen Fixation on Carbon Atom
}

\author{
Hayoung Song ${ }^{[a]}$ and Eunsung Lee ${ }^{[a, b]^{*}}$ \\ [a] H. Song, Prof. E. Lee \\ Department of Chemistry, Pohang University of Science and Technology (POSTECH), Pohang, 37673, Republic of Korea \\ E-mail: eslee@postech.ac.kr (E. Lee) \\ [b] Prof. E. Lee \\ Graduate school of artificial intelligence, Pohang University of Science and Technology. Pohang, 37673, Republic of Korea. \\ Supporting information for this article is given via a link at the end of the document
}

\begin{abstract}
Dinitrogen activation in non-metallic systems has received considerable attention in recent years. Herein, we report the theoretical feasibility of $\mathrm{N}_{2}$ fixation using aminocarbenes (L) or their anionic derivatives. The molecular descriptors of $L$ and anionic $\mathbf{L}^{-}$, which affect the interaction of $L$ and anionic $\mathbf{L}^{-}$with $\mathrm{N}_{2}$, were identified through multiple linear regression analysis. Additionally, the electron flow during $\mathrm{C}-\mathrm{N}$ bond formation was confirmed by performing intrinsic reaction coordination calculations with intrinsic bond orbital analysis for the reaction of anionic $\mathrm{L}^{-}$with $\mathrm{N}_{2}$.
\end{abstract}

Dinitrogen $\left(\mathrm{N}_{2}\right)$ is the most abundant and easily accessible nitrogen source in nature. The synthesis of useful chemicals using $\mathrm{N}_{2}$, from $\mathrm{NH}_{3}{ }^{[1]}$ to $\mathrm{N}$-containing organic molecules ${ }^{[2]}$, has a long history and is still considered most challenging in chemistry. The development of systems for metal-free $\mathrm{N}_{2}$ fixation is particularly difficult. Recently, boron-containing organic materials have attracted attention as materials for metal-free $\mathrm{N}_{2}$ fixation. The fixation and electrocatalytic reduction of $\mathrm{N}_{2}$ using graphene doped with boron were reported by Zheng et al..$^{[3]}$ The Braunschweig group also reported the fixation and reduction of $\mathrm{N}_{2}$ using organic borylene. ${ }^{[4]} \mathrm{Zhu}$ et al. reported the theoretical systematic design of frustrated Lewis pairs using a highly Lewis acidic borole as the active site, with $\mathrm{N}$-heterocyclic carbenes (NHCs). ${ }^{\left[{ }^{[}\right]}$However, to date, there are no reported examples of $\mathrm{N}_{2}$ fixation using only carbon active sites.

Persistent aminocarbenes, represented by $\mathrm{NHCs}$, have been utilized for metal-free small-molecule activation. Persistent aminocarbenes successfully react with $\mathrm{CO}_{2}, \mathrm{SO}_{2}, \mathrm{NO}$, and $\mathrm{N}_{2} \mathrm{O}$ as well as inert molecules such as $\mathrm{H}_{2}$ and $\mathrm{CO}^{\left[{ }^{[6]}\right.}$ Furthermore, the metal-free catalytic conversion of $\mathrm{CO}^{[7]}$ over an aminocarbene catalyst was also reported. Considering that $\mathrm{CO}$ is isoelectronic with $\mathrm{N}_{2}$, aminocarbene can be effectively utilized as the carbon active site for $\mathrm{N}_{2}$ fixation.

Herein, we report theoretical studies on $\mathrm{N}_{2}$ fixation on carbon atoms. We explored 20 typical examples of aminocarbene $(\mathbf{L})^{[8]}$ in five binding modes with $\mathrm{N}_{2}$ (Figure 1). We confirmed that although thermodynamically favored products can be obtained from the reaction of $L$ and $N_{2}$, the reaction is not kinetically favored. The thermodynamic and kinetic effects on the interaction between $\mathbf{L}$ and $\mathrm{N}_{2}$ were investigated using the molecular descriptor $\mathbf{L}$. We also reported that the anionic $\mathrm{L}^{-}$radical can overcome the high activation barrier of $L$ in the reaction with $\mathrm{N}_{2}$.

First, we attempted to establish possible candidates that could be obtained from the reaction of $L$ with $\mathrm{N}_{2}$. With the proposal that the reactivity of $\mathrm{NHCs}$ can mimic the reactivity of transition metals, [6a] we proposed five structures of possible products based on previously reported transition metal- $\mathrm{N}_{2}$ complexes (Figure 1). ${ }^{[9]}$ The ligand hapticity of $N_{2}$ has been reported for both $\eta^{1}$ and $\eta^{2}$ for transition metal- $\mathrm{N}_{2}$ complexes. Thus, $\mathrm{L}\left(\eta^{1}-\mathrm{N}_{2}\right)$ and $\mathrm{L}\left(\eta^{2}-\mathrm{N}_{2}\right)$ were chosen as mononuclear $\mathbf{L}\left(\mathrm{N}_{2}\right)$ complexes. Furthermore, referring to the examples of the reported bimetallic $\mathrm{N}_{2}$ complexes, ${ }^{[9]} \mathbf{L}_{2}(\mu-$ $\left.\eta^{1}: \eta^{1}-N_{2}\right), L_{2}\left(\mu-\eta^{2}: \eta^{2}-N_{2}\right)$, and $L_{2}\left(\mu-\eta^{1}: \eta^{2}-N_{2}\right)$ were also selected as binuclear $L_{2}\left(N_{2}\right)$ complexes. $L\left(\eta^{1}-N_{2}\right)$ and $L\left(\eta^{2}-N_{2}\right)$ can be considered as diazoalkane and diazirine derivatives, which have been actively used as precursors of transient carbenes. $\mathbf{L}_{2}(\mu-$ $\left.\eta^{1}: \eta^{1}-N_{2}\right)$ can also be considered an azoalkane derivative. Each structure was optimized by Gaussian 16 using the B3LYP functional with the Def2-SVP basis set.

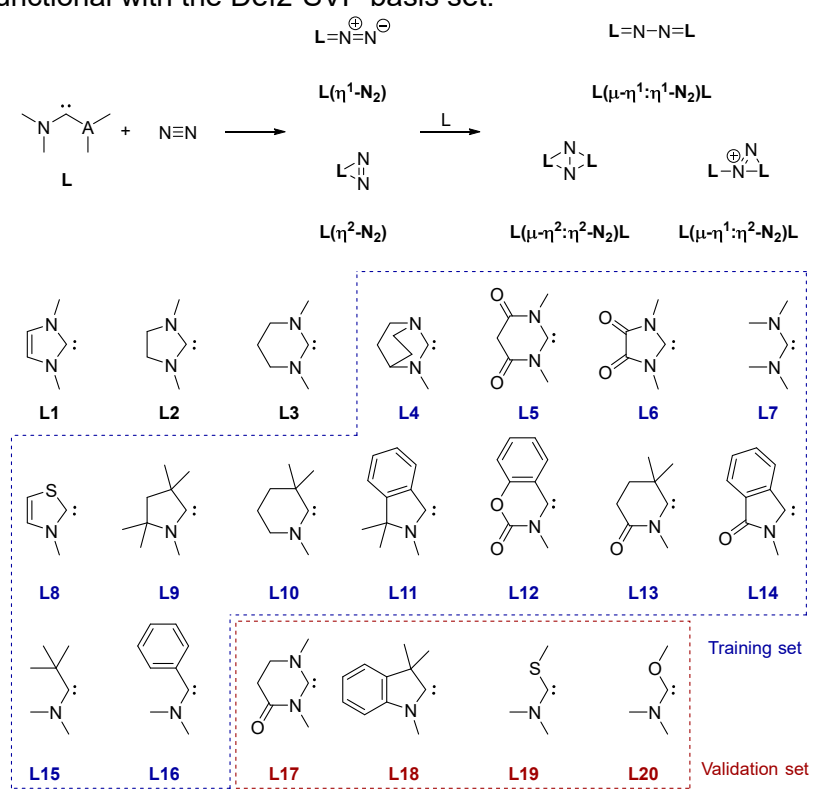

Figure 1. Selected training/validation aminocarbene $L$ sets on five $L-N_{2}$ binding modes. 


\begin{tabular}{|c|c|c|c|c|}
\hline $\begin{array}{c}\Delta \mathrm{G} \\
(\mathrm{kcal} / \mathrm{mol})\end{array}$ & TS1 & $L\left(\eta^{1}-N_{2}\right)$ & TS2 & $L_{2}\left(\mu-\eta^{1}: \eta^{1}-N_{2}\right)$ \\
\hline L4 & 43.7 & 38.4 & 53.3 & -26.4 \\
\hline L5 & 39.8 & 35.9 & 50.3 & -14.1 \\
\hline L6 & 39.6 & 35.8 & 47.1 & -31.3 \\
\hline L7 & 47.0 & 36.9 & 59.8 & -15.2 \\
\hline L8 & 54.4 & 53.8 & 65.6 & 2.3 \\
\hline L9 & 37.0 & 33.6 & 45.2 & -30.1 \\
\hline L10 & 32.7 & 24.5 & 48.8 & -24.7 \\
\hline L11 & 37.9 & 30.1 & 43.4 & -36.0 \\
\hline L12 & 33.2 & 21.2 & 32.5 & -34.2 \\
\hline L13 & 30.4 & 14.4 & 29.5 & -43.7 \\
\hline L14 & 27.5 & 10.3 & 20.3 & -56.9 \\
\hline L15 & 31.4 & 16.0 & 33.2 & -26.1 \\
\hline L16 & 31.9 & 19.4 & 34.6 & -24.0 \\
\hline L17 & 45.9 & 44.3 & 59.4 & -5.8 \\
\hline L18 & 36.3 & 26.6 & 39.6 & -42.3 \\
\hline L19 & 45.3 & 35.8 & 62.5 & -3.2 \\
\hline L20 & 50.0 & 47.4 & 64.7 & -5.2 \\
\hline
\end{tabular}
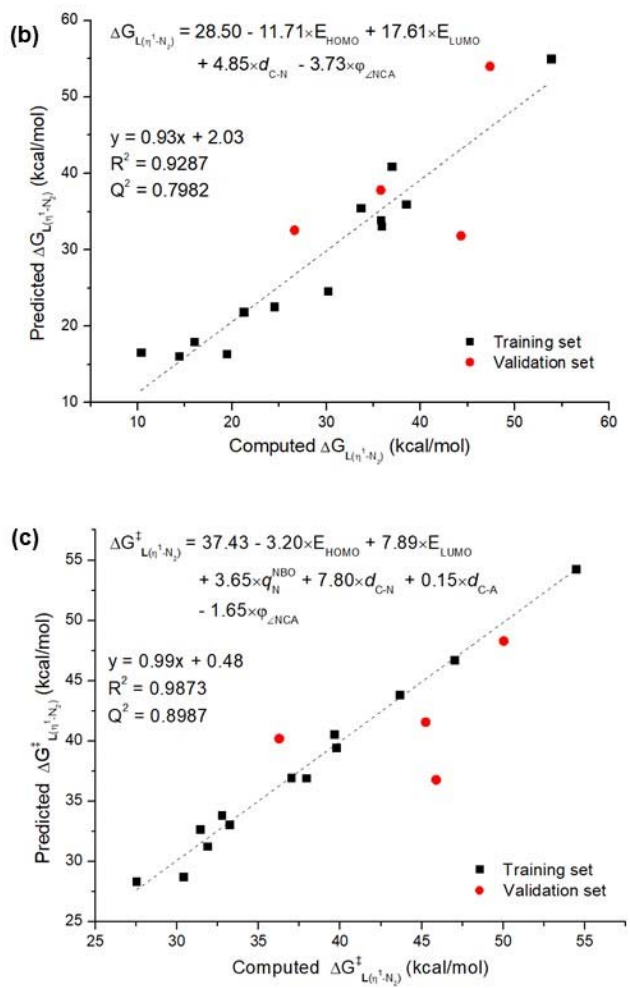

Figure 2. (a) Detailed free energies of the formation of $L-N_{2}$ complex and its transition states. (b) Comprehensive model of the free energy of $L\left(\eta^{1}-N_{2}\right)$ formation. (c) Comprehensive model of the activation barrier of $L\left(\eta^{1}-\mathrm{N}_{2}\right)$ formation (computed using Gaussian 16 at the B3LYP/Def2-SVP level).

As a result, the formation of $L\left(\eta^{1}-N_{2}\right), L\left(\eta^{2}-N_{2}\right)$, and $L_{2}\left(\mu-\eta^{2}: \eta^{2}-\right.$ $\mathrm{N}_{2}$ ) was thermodynamically unfavorable for all $L$ (Figure 2a). Unfortunately, the structure optimization of $L_{2}\left(\mu-\eta^{1}: \eta^{2}-N_{2}\right)$ for some $\mathbf{L}$ failed; however, the formation of other successfully optimized $L_{2}\left(\mu-\eta^{1}: \eta^{2}-N_{2}\right)$ was thermodynamically unfavorable, except for L13 and L14. The formation of $L_{2}\left(\mu-\eta^{1}: \eta^{1}-N_{2}\right)$ was thermodynamically preferred for most $\mathbf{L}$, except for $\mathbf{L} \mathbf{1}$ to $\mathbf{L} 3$ and L8. Therefore, we chose $L_{2}\left(\mu-\eta^{1}: \eta^{1}-N_{2}\right)$ as a suitable model for $N_{2}$ fixation on carbon atoms.

Despite the high thermodynamic stability of $L_{2}\left(\mu-\eta^{1}: \eta^{1}-N_{2}\right)$, the real challenge for dinitrogen fixation on carbon atoms is that the formation of intermediate $L\left(\eta^{1}-N_{2}\right)$ is kinetically and thermodynamically unfavorable. We confirmed the high activation barrier for the formation of $\mathbf{L}\left(\eta^{1}-N_{2}\right) \quad\left(\Delta G^{\ddagger}\left(L\left(\eta^{1}-N_{2}\right)\right)=27-55\right.$ $\mathrm{kcal} / \mathrm{mol}$ ) between $\mathbf{L} 4$ and $\mathbf{L} 20$ (Figure $2 \mathrm{a}$ ). The activation barrier for the formation of $L_{2}\left(\mu-\eta^{1}: \eta^{1}-N_{2}\right)$ from $L\left(\eta^{1}-N_{2}\right)$ was relatively low $\left(\Delta G^{\ddagger}\left(\mathbf{L}_{2}\left(\mu-\eta^{1}: \eta^{1}-N_{2}\right)\right)=10-27 \mathrm{kcal} / \mathrm{mol}\right)$.

We identified the correlation of $\Delta \mathrm{G}$ and $\Delta \mathrm{G}^{\ddagger}$ with the normalized molecular descriptors for $\mathbf{L}$ through multiple linear regression (MLR) analysis. ${ }^{[10]}$ Considering the small size of dinitrogen, steric descriptors, such as $V_{\text {bur }}$ and Sterimol parameters, were omitted from the selection of the molecular descriptor of $L$. We selected the molecular descriptor for MLR analysis using a correlation map to remove multicollinearity of the selected molecular descriptors (Figures S1 and S2).

Because of the strong correlation between $\Delta G\left(L\left(\eta^{1}-N_{2}\right)\right)$ and $\Delta G^{\ddagger}\left(L\left(\eta^{1}-N_{2}\right)\right) \quad\left(R^{2}=0.93\right)$, similar models were produced by performing MLR on selected molecular descriptors with the robustness of the correlations $\left(R^{2}=0.92\right.$ for Figure $2 b$ and $R^{2}=$ 0.98 for Figure $2 c)$. $\Delta G\left(L\left(\eta^{1}-N_{2}\right)\right)$ strongly depends on $E_{\text {номо }}$ and $E_{\text {LUMO }}$ and weakly on $d_{\mathrm{C}-\mathrm{N}}$ and $\varphi_{\angle \mathrm{NCA}}$. Similarly, $\Delta \mathrm{G}^{\ddagger}\left(\mathbf{L}\left(\eta^{1}-\mathrm{N}_{2}\right)\right)$ depends on $\mathrm{E}_{\text {HOMO }}, \mathrm{E}_{\mathrm{LUMO}}, q^{\mathrm{NBO}}{ }_{\mathrm{N}}, d_{\mathrm{C}-\mathrm{N}}$, and $\varphi_{\angle \mathrm{NCA}}$ and weakly on $d_{\text {C-A. }}$. Commonly, $\Delta G\left(L\left(\eta^{1}-N_{2}\right)\right)$ and $\Delta G^{\ddagger}\left(L\left(\eta^{1}-N_{2}\right)\right)$ are more dependent on $\mathrm{E}_{\mathrm{LUMO}}$ than on $\mathrm{E}_{\text {HOMO }}$, indicating that the reactivity of $L$ with $\mathrm{N}_{2}$ was more influenced by the Lewis acidity of $L$.

For $\mathrm{N}_{2}$ fixation using $\mathbf{L}$ without additional reagents, it is necessary to design an ambiphilic $\mathbf{L}$ with high HOMO and low LUMO energy levels. However, the low thermal stability ${ }^{[8,}{ }^{11]}$ of previously reported ambiphilic aminocarbenes is not suitable for overcoming the high activation barrier $\left(\Delta G^{\ddagger}\left(L\left(\eta^{1}-N_{2}\right)\right)>27\right.$ $\mathrm{kcal} / \mathrm{mol})$ for the formation of $L\left(\eta^{1}-\mathrm{N}_{2}\right)$.

Instead of designing a new ambiphilic aminocarbene with high thermal stability, we proposed another strategy for $\mathrm{N}_{2}$ fixation using previously reported $\mathbf{L}$ to achieve a low activation barrier for $\mathrm{N}_{2}$ fixation. Low-valent transition metal complexes have received continuous interest as promising catalyst candidates for $\mathrm{N}_{2}$ fixation and catalytic reduction. ${ }^{[12]}$ The high electron density of the low-valence transition metal allows the formation of a stable $\mathrm{N}_{2}$ complex through strong $\pi$-backdonation on the $\mathrm{N}_{2}$ ligand. We proposed that the aminocarbene derivatives $\mathbf{L}$, mimicking the reactivity of transition metals, can form stable $L\left(\eta^{1}-N_{2}\right)$ radical anions via one-electron reduction. 


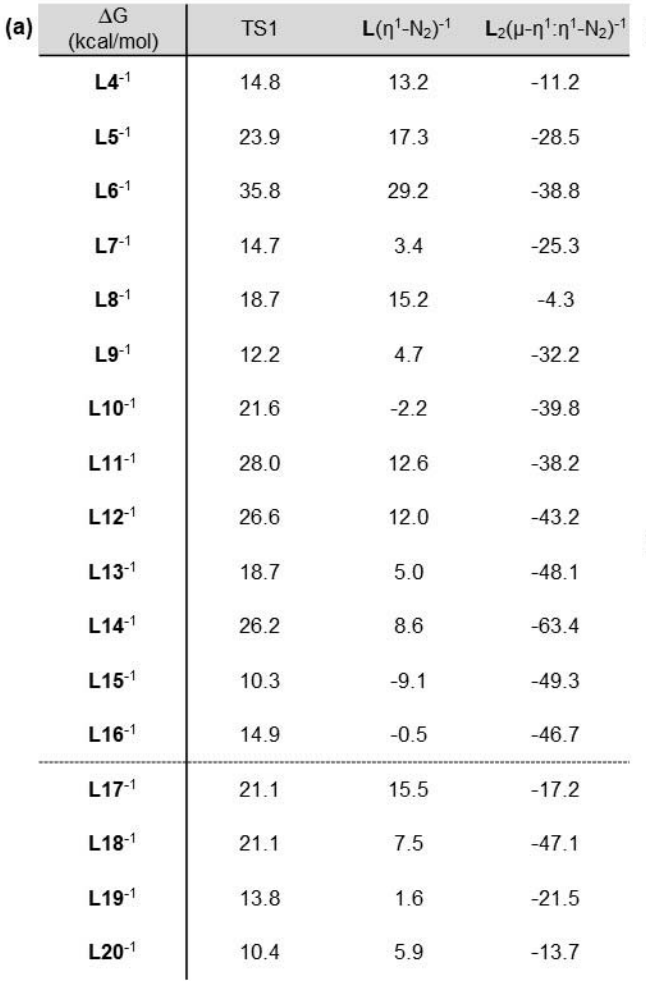

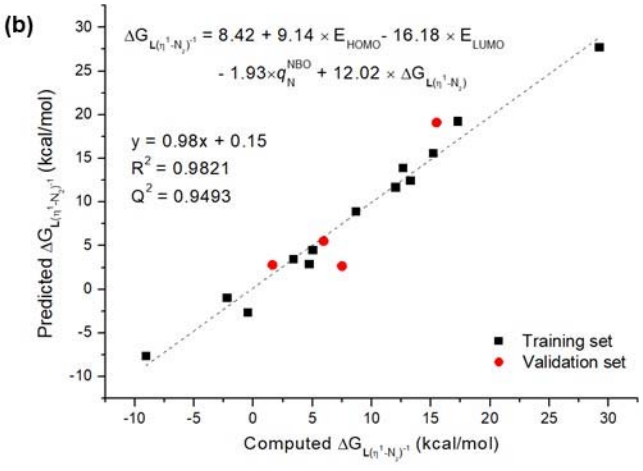

(c)

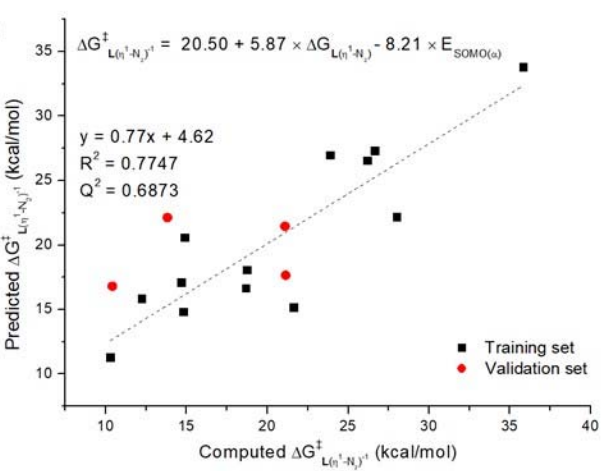

Figure 3. (a) Detailed free energies of the formation of the anionic $\mathrm{L}^{-}-\mathrm{N}_{2}$ complex and its transition state. (b) Comprehensive model of the free energy of anionic $\mathbf{L}\left(\eta^{1}-\mathrm{N}_{2}\right)^{-}$formation. (c) Comprehensive model of the activation barrier of anionic $\mathrm{L}\left(\eta^{1}-\mathrm{N}_{2}\right)^{-}$formation. (computed using Gaussian 16 at the B3LYP/Def2-SVP level)

The structures of anionic $\mathbf{L}^{-}, \mathbf{L}\left(\eta^{1}-\mathrm{N}_{2}\right)^{-}$and $\mathrm{L}_{2}\left(\mu-\eta^{1}: \eta^{1}-\mathrm{N}_{2}\right)^{-}$ radicals and their transition states were optimized at the B3LYP/Def2-SVP level. The results indicated that the formation of anionic $L\left(\eta^{1}-N_{2}\right)^{-}$and $L_{2}\left(\mu-\eta^{1}: \eta^{1}-N_{2}\right)^{-}$radicals is thermodynamically more favored than that of neutral $L\left(\eta^{1}-N_{2}\right)$ (Figure 3a). The formation of $L\left(\eta^{1}-N_{2}\right)$ radical anions was slightly exothermic for L10, L15, and L16 $(-2.2,-9.1$, and $-0.5 \mathrm{kcal} / \mathrm{mol})$. Furthermore, we confirmed that the activation barrier of the reaction between the anionic radical derivatives of $L$ and $N_{2}$ decreased drastically. For example, the free energy of $L 9\left(\eta^{1}-N_{2}\right)$ formation decreased from $33.6 \mathrm{kcal} / \mathrm{mol}$ to $4.7 \mathrm{kcal} / \mathrm{mol}$, and its activation barrier also significantly decreased from $37.0 \mathrm{kcal} / \mathrm{mol}$ to $12.2 \mathrm{kcal} / \mathrm{mol}$ (Figure 4). The activation barrier of $\mathbf{L} \mathbf{9}_{2}\left(\mu-\eta^{1}: \eta^{1}-\right.$ $\mathrm{N}_{2}$ ) formation was also decreased from $11.6 \mathrm{kcal} / \mathrm{mol}$ to 6.8 $\mathrm{kcal} / \mathrm{mol}$. However, the activation barrier of $L\left(\eta^{1}-\mathrm{N}_{2}\right)$ formation for L6, L11, L12, and L14 radical anions, which are highly ambiphilic aminocarbenes, was not significantly decreased. $\left(\Delta \Delta G^{\ddagger}<10\right.$ $\mathrm{kcal} / \mathrm{mol})$.

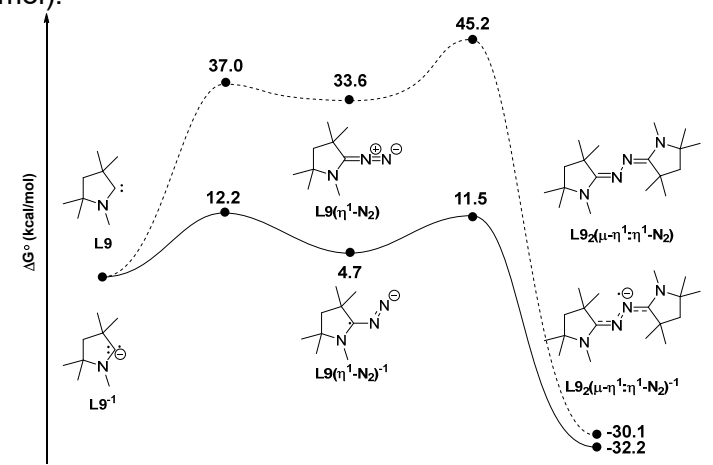

Figure 4. Free energy profile of the reaction of $\mathbf{L} \mathbf{9}$ and $\mathbf{L} \mathbf{9}^{-1}$ with $\mathrm{N}_{2}$ as calculated using Gaussian 16 at the B3LYP/Def2-SVP level.
We also performed MLR analysis to determine how the molecular descriptors of $\mathbf{L}$ affect the free energy and activation barrier of anionic $L\left(n^{1}-N_{2}\right)^{-}$formation. We considered both the molecular descriptors of neutral and anionic $\mathbf{L}^{-}$. In addition, the free energy and activation barrier of neutral $L\left(\eta^{1}-N_{2}\right)$ formation were considered as additional molecular descriptors. In the removal of multicollinearity using the correlation maps of selected parameters, the molecular descriptors of neutral $\mathbf{L}$ were selected prior to the molecular descriptors of anionic $\mathrm{L}^{-}$(Figure S1).

Interestingly, there is a relatively low correlation between the free energy of anionic $L\left(\eta^{1}-N_{2}\right)^{-}$formation and its activation barrier $\left(R^{2}\right.$ $=0.52)$, unlike neutral $\mathbf{L}\left(\eta^{1}-\mathrm{N}_{2}\right)$ formation $\left(R^{2}=0.93\right)$ (Figures $\mathbf{S 1}$ and $\mathbf{S 2}$ ). The free energy and activation barrier of the $L\left(\eta^{1}-N_{2}\right)$ radical anion were significantly dependent on the free energy of neutral $L\left(\eta^{1}-N_{2}\right)$ (Figure $\mathbf{3 b}$ and $\mathbf{3 c}$ ). In addition, the free energy of the $\mathbf{L}\left(\eta^{1}-\mathrm{N}_{2}\right)$ radical anion decreased with decreasing $\mathrm{E}_{\text {номо }}$ and increasing $E_{\text {LUMO }}$ of neutral $\mathbf{L}$. However, the activation barrier of the formation of the $L\left(\eta^{1}-N_{2}\right)$ radical anion decreased significantly with increasing $\mathrm{E}_{\mathrm{SOMO}(\alpha)}$ of anionic $\mathrm{L}^{-}$. This result indicates that the $\operatorname{SOMO}(\alpha)$ of anionic $\mathrm{L}^{-}$largely contributes to the reaction of $\mathbf{L}$ with $\mathrm{N}_{2}$.

Intrinsic reaction coordination calculations and intrinsic bond orbital (IBO) analysis ${ }^{[13]}$ were performed to confirm the electron flow during $\mathrm{C}-\mathrm{N}$ bond formation between anionic $\mathrm{L9}$ and $\mathrm{N}_{2}$ (Figure 5). In the optimized transition state, $\mathrm{N}_{2}$ approached the vertical direction of the carbene. Thus, $\sigma$-bond formation between the $\pi^{*}$ orbital of $\mathrm{N}_{2}$ and the $\operatorname{SOMO}(\alpha)$ of anionic $\mathrm{L}^{-}$occurred preferentially. Thereafter, the new $\pi$-bond derived from the $\mathrm{HOMO}$ was formed when the other $\pi^{*}$ orbital of $\mathrm{N}_{2}$ and the $\mathrm{HOMO}$ of anionic $\mathrm{L}^{-}$were sufficiently close. 

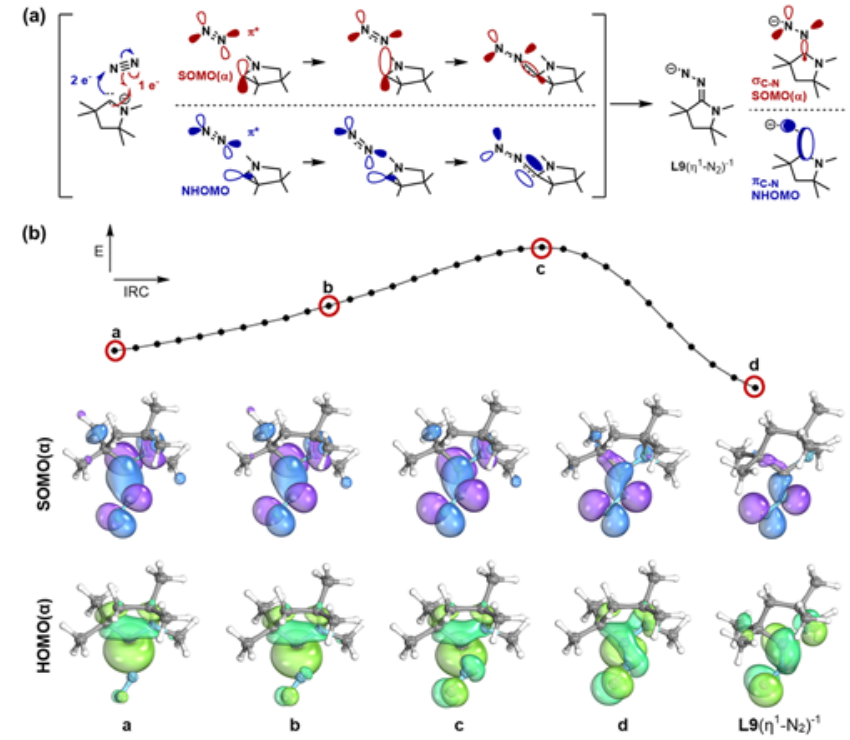

Figure 5. Mechanism of electron flow during the reaction between anionic $\mathrm{L}^{-}$ and $\mathrm{N}_{2}$ visualized through IBO analysis.

In summary, we confirmed that the reactivity of $L$ with $\mathrm{N}_{2}$ was influenced by their HOMO and LUMO energy levels, $\mathrm{C}-\mathrm{N}$ and $\mathrm{C}-$ A bond lengths, bond angles of $\mathrm{N}-\mathrm{C}-\mathrm{A}$, and nitrogen atom charges. From these results, we discovered that $\mathrm{N}_{2}$ fixation using the anionic $\mathrm{L}^{-}$radical significantly lowers the activation energy of the reaction of $L$ with $N_{2}$ via the interaction between the $\operatorname{SOMO}(\alpha)$ of $\mathrm{L}^{-}$and the $\pi^{*}$ orbital of $\mathrm{N}_{2}$. This study suggested that $\mathrm{N}_{2}$ fixation on carbon atoms can be achieved through the design of (1) thermodynamically highly stable ambiphilic aminocarbenes or (2) aminocarbenes capable of one-electron reduction, which can serve as an important route for the entry of non-metallic systems.

\section{Acknowledgements}

This work was supported by the National Supercomputing Center with supercomputing resources including technical support (KSC2019-CRE-0162), and by the National Research Foundation of Korea (NRF-2019R1A2C2010732).

Keywords: Dinitrogen, Carbene, $\mathrm{N}_{2}$ fixation, N-heterocyclic carbene, DFT calculation

[1] (a) B. M. Hoffman, D. Lukoyanov, Z.-Y. Yang, D. R. Dean, L. C. Seefeldt, Chem. Rev. 2014, 114, 4041-4062; (b) R. R. Schrock, Acc. Chem. Res. 2005, 38, 955-962; (c) M. J. Chalkley, T. J. Del Castillo, B. D. Matson, J. P. Roddy, J. C. Peters, ACS Cent. Sci. 2017, 3, 217-223; (d) Y. Nishibayashi, Dalton Trans. 2018, 47, 11290-11297.

[2] (a) M. Mori, J. Organomet. Chem. 2004, 689, 4210-4227; (b) A. J. Keane, W. S. Farrell, B. L. Yonke, P. Y. Zavalij, L. R. Sita, Angew. Chem. Int. Ed. 2015, 54, 10220-10224; (c) J. J. Curley, A. F. Cozzolino, C. C. Cummins, Dalton Trans. 2011, 40, 2429-2432; (d) I. Klopsch, M. Kinauer, M. Finger, C. Würtele, S. Schneider, Angew. Chem. Int. Ed. 2016, 55, 4786-4789; (e) S. F. McWilliams, D. L. J. Broere, C. J. V. Halliday, S. M. Bhutto, B. Q. Mercado, P. L. Holland, Nature 2020, 584, 221-226.

[3] X. Yu, P. Han, Z. Wei, L. Huang, Z. Gu, S. Peng, J. Ma, G. Zheng, Joule 2018, 2, 1610-1622.
[4] (a) M.-A. Légaré, G. Bélanger-Chabot, R. D. Dewhurst, E. Welz, I. Krummenacher, B. Engels, H. Braunschweig, Science 2018, 359, 896900; (b) M.-A. Légaré, M. Rang, G. Bélanger-Chabot, J. I. Schweizer, I. Krummenacher, R. Bertermann, M. Arrowsmith, M. C. Holthausen, H. Braunschweig, Science 2019, 363, 1329-1332; (c) M.-A. Légaré, G. Bélanger-Chabot, M. Rang, R. D. Dewhurst, I. Krummenacher, R. Bertermann, H. Braunschweig, Nat. Chem. 2020, 12, 1076-1080.

[5] (a) A. M. Rouf, C. Dai, F. Xu, J. Zhu, Adv. Theory Simul. 2020, 3, 1900205; (b) A. M. Rouf, C. Dai, S. Dong, J. Zhu, Inorg. Chem. 2020, 59, 11770-11781; (c) A. M. Rouf, Y. Huang, S. Dong, J. Zhu, Inorg. Chem. 2021, 60, 5598-5606.

[6] (a) D. Martin, M. Soleilhavoup, G. Bertrand, Chem. Sci. 2011, 2, 389399; (b) H. Song, Y. Kim, J. Park, K. Kim, E. Lee, Synlett 2016, 27, 477-485.

[7] (a) X. Li, K. Liu, X. Xu, L. Ma, H. Wang, D. Jiang, Q. Zhang, C. Lu, Chem. Commun. 2011, 47, 7860-7862; (b) J. L. Peltier, E. TomásMendivil, D. R. Tolentino, M. M. Hansmann, R. Jazzar, G. Bertrand, J. Am. Chem. Soc. 2020, 142, 18336-18340.

[8] (a) A. J. Arduengo, R. L. Harlow, M. Kline, J. Am. Chem. Soc. 1991, 113, 361-363; (b) A. J. Arduengo, J. R. Goerlich, W. J. Marshall, J. Am. Chem. Soc. 1995, 117, 11027-11028; (c) R. W. Alder, M. E. Blake, C. Bortolotti, S. Bufali, C. P. Butts, E. Linehan, J. M. Oliva, A. Guy Orpen, M. J. Quayle, Chem. Commun. 1999, 241-242; (d) D. Martin, N. Lassauque, B. Donnadieu, G. Bertrand, Angew. Chem. Int. Ed. 2012, 51, 6172-6175; (e) T. W. Hudnall, C. W. Bielawski, J. Am. Chem. Soc. 2009, 131, 16039-16041; (f) M. Braun, W. Frank, G. J. Reiss, C. Ganter, Organometallics 2010, 29, 4418-4420; (g) R. W. Alder, P. R. Allen, M. Murray, A. G. Orpen, Angew. Chem. Int. Ed. Engl. 1996, 35, 1121-1123; (h) A. J. Arduengo III, J. R. Goerlich, W. J. Marshall, Liebigs Ann. 1997, 1997, 365-374; (i) V. Lavallo, Y. Canac, C. Präsang, B. Donnadieu, G. Bertrand, Angew. Chem. Int. Ed. 2005, 44, 57055709; (j) C. M. Weinstein, G. P. Junor, D. R. Tolentino, R. Jazzar, M. Melaimi, G. Bertrand, J. Am. Chem. Soc. 2018, 140, 9255-9260; (k) B. Rao, H. Tang, X. Zeng, L. L. Liu, M. Melaimi, G. Bertrand, Angew. Chem. Int. Ed. 2015, 54, 14915-14919; (I) H. Song, H. Kim, E. Lee, Angew. Chem. Int. Ed. 2018, 57, 8603-8607; (m) Z. R. McCarty, D. N. Lastovickova, C. W. Bielawski, Chem. Commun. 2016, 52, 5447-5450; (n) P. R. Sultane, G. Ahumada, D. Janssen-Müller, C. W. Bielawski, Angew. Chem. Int. Ed. 2019, 58, 16320-16325; (o) M. B. Gildner, T. W. Hudnall, Chem. Commun. 2019, 55, 12300-12303; (p) V. Lavallo, J. Mafhouz, Y. Canac, B. Donnadieu, W. W. Schoeller, G. Bertrand, J. Am. Chem. Soc. 2004, 126, 8670-8671; (q) X. Cattoën, H. Gornitzka, D. Bourissou, G. Bertrand, J. Am. Chem. Soc. 2004, 126, 1342-1343; (r) G. A. Blake, J. P. Moerdyk, C. W. Bielawski, Organometallics 2012, 31, 3373-3378; (s) H. Kim, M. Kim, H. Song, E. Lee, Chem. Eur. J. 2021, 27, 3849-3854; (t) R. W. Alder, C. P. Butts, A. G. Orpen, J. Am. Chem. Soc. 1998, 120, 11526-11527.

[9] P. L. Holland, Dalton Trans. 2010, 39, 5415-5425.

[10] J.-Y. Guo, Y. Minko, C. B. Santiago, M. S. Sigman, ACS Catal. 2017, 7 , 4144-4151.

[11] (a) S. Solé, H. Gornitzka, W. W. Schoeller, D. Bourissou, G. Bertrand, Science 2001, 292, 1901-1903; (b) J. Vignolle, M. Asay, K. Miqueu, D. Bourissou, G. Bertrand, Org. Lett. 2008, 10, 4299-4302; (c) J. Lorkowski, M. Krahfuß, M. Kubicki, U. Radius, C. Pietraszuk, Chem. Eur. J. 2019, 25, 11365-11374.

[12] M. J. Chalkley, M. W. Drover, J. C. Peters, Chem. Rev. 2020, 120, 5582-5636.

[13] G. Knizia, J. E. M. N. Klein, Angew. Chem. Int. Ed. 2015, 54, 55185522 